\title{
О ТЕПЛОТЕ РАЗЛОЖЕНИЯ ОРГАНИЧЕСКОГО ВЕЩЕСТВА ЭСТОНСКИХ ГОРЮЧИХ СЛАНЦЕВ *
}

\author{
Р. ВАЛДЕК, Н. Л. ЛУЦКОВСКАЯ, \\ кандидаты технических наук \\ ю. ЭИЗЕН
}

Горючие сланцы Эстонской ССР следует рассматривать не только как энергетическое топливо, но и как ценное технологнческое сырье для термической переработки. В то же время теоретические основы термической переработки горючих сланцев еще недостаточно разработаны. Так, при расчете расхода тепла для термической переработки сланца в различных промышленных агрегатах необходимо знать величнну теплоты термического разложения органического вещества (керогена) перерабатываемого сланца, а также изменение теплоемкости исследуемого сланца в пропесс его нагревания. Для вычисления же этих величин в настоящее время имеется очень мало данных.

Термографическими исследованиями горючих сланцев, проведенными рядом отечественных $\left[{ }^{1-4}\right]$ и зарубежных авторов, качественно установлено, что процесс разложения органического вещества горючих сланцев представляет собой эндотермический процесс. Вопрос же об острой необходимости количественного определения теплоты разложения органического вещества горючих сланцев был поставлен еще в 1946 г. [5]

Ввиду сложности состава горючих сланцев и трудности работы с ними при повышенных температурах в печати имеется только одна работа [ $\left.{ }^{6}\right]$, посвященная экспериментальному количественному определению теплоты разложения органического вещества прибалтийского сланца при температуре полукоксования. Следует, однако, отметить, что выбранный авторами метод страдает рядом погрешностей, вследствие чего и полученные ими параллельные данные $(-157$ и -30 кал) резко (больше чем в 5 раз) отличаются друг от друга. Поэтому данные по теплоте термического разложения органического вещества горючих сланцев, полученные в названной работе, могут рассматриваться только как ориентировочные, что справедливо отмечают и сами авторы.

Для более точного определения теплоты разложения органического вещества горючих сланцев необходимо провести опыты по методике, исключающей конденсацию жидких продуктов в калориметрической системе.

В настоящей работе при определении теплоты термического разложения органического вещества сланца-кукерсита за основу была принята количественная термография с учетом специфики работы с горючими сланцами. Применялся метод сравнения площадей на дифференциальной кривой нагревания, полученных при термическом разложении исследуемого образца и эталонного вещества с известным тепловым эффектом. Термографическая запись проводилась на фоторегистрирующем пирометре ФПК-55. Линейный подъем температуры печи со скоростью около 9 град/мин осуществлялся с помощью специального программного регулятора температуры.

* В экспериментальной части работы принимал участие инженер А. Верк. 
В работе использовалась комбинированная термопара, один горячий спай которой, присоединенный к гальванометру простой записи, помешался в исследуемый образец, а второй - в эталонное вещество (не имеющее тепловых эффектов в пределах изучаемых температур). Эталонным веществом служила прокаленная безводная окись алюминия.

Основным положением методики данной работы является то, что на дифференциальных кривых нагревания площадь теплового эффекта пропорциональна массе термоактивного вещества, т. е. вещества, претерпевающего те или иные изменения, сопровождающиеся определяемым эффектом. Для проверки этого положения, а также для установления возможностей применения его при работе с горючими сланцами был проведен рял проверочных, поисковых опытов.

Опыты с различными навесками бикарбоната натрия, с гипсом, а также с рядом образцов горючего сланца показали, что не всегда с увеличением навески исследуемого вещества прямо пропорционально увеличивается и площадь соответствующего эффекта, хотя в большинстве случаев эта закономерность и подтверждается. Изучение полученных кривых показало, что в большинстве случаев после завершения процесса, обусловливающего тепловой эффект, уровень средней нулевой линии $(\Delta t=0)$ изменяется, что обычно вызывается изменением теплопоглощения исследуемого вещества вследствие изменения его массы и химического состава. Изменение уровня нулевой линии затрудняет правильное ограничение площади теплового эффекта.

При ограничении площади возможны два варианта: 1) соединение по прямой точек начала и конца эффекта и 2) восстановление перпендикуляра из точек экстремума и пересечение его с параллельными линиями, соответствующими нулевым линиям перед началом и после окончания эффекта, и соединение начала и конца эффекта волнообразной линией, учитывая, что в начале процесса, обусловливающего тепловой эффект, теплопоглощение исследуемого образца ближе к теплопоглощению первоначального, исходного вещества, а в конце процесса - к теплопоглощению получившегося вещества (фиг. 1).

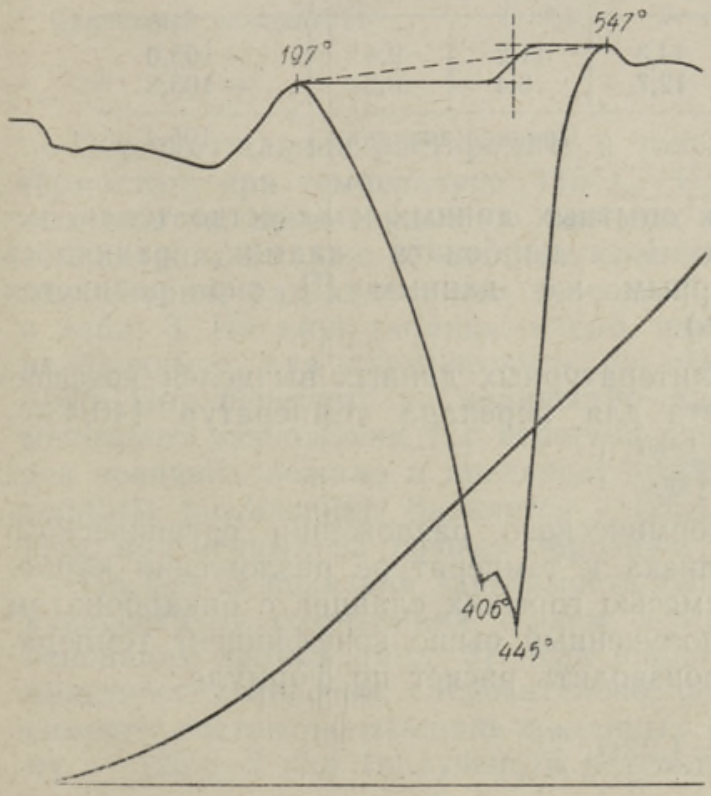

$\Phi_{\text {иг. } 1 .}$

Ограничение площади эффекта:

-- - п прямой. линией, волнообразной линией. 
Сопоставление данных различных опытов, в которых было проведено ограничение площадей эффектов прямыми и волнообразными линиями, показало, что в случае ограничения волнообразными линиями достигается лучшая сходимость результатов параллельных опытов. Все результаты, приведенные в настоящей работе, получены при ограничении площади эффекта волнообразной линией.

Несмотря на неполное соответствие между навеской и площадью, занимаемой эффектом в первых поисковых опытах, средние данные по числу калорий, приходящихся на $1 \mathrm{~cm}^{2}$ площади эффектов, для бикарбоната натрия и гипса получились очень близкими - соответственно 2,43 и 2,38 кал/см². Такое хорошее совпадение указывает на возможность применения данной методики для исследования, но вместе с тем и на необходимость проведения достаточного числа опытов для получения среднего значения, так как при небольшом количестве опытов могут быть получены случайные искажения за счет неточностей в воспроизведении условий опытов.

Для избежания невоспроизводимости условий опыта исследуемого и эталонного веществ следует проводить исследование их смеси, состоящей из точных навесок обоих, и сопоставлять эффекты, полученные на одной кривой нагревания. Но в этом случае будет наблюдаться ошибка за счет большой разности температур, при которых проходят процессы эталонного и исследуемого веществ. Для того чтобы учесть эту ошибку, необходимо определить коэффициент температурного пересчета, что и делалось в настоящей работе на смеси бикарбоната натрия и карбоната кадмия. Результаты параллельных опытов приведены в табл. 1 .

\section{Таблица I}

Результаты исследования смеси $\mathrm{CdCO}_{3}$ и $\mathrm{NaHCO}_{3}$, разбавленной $\mathrm{Al}_{2} \mathrm{O}_{3}$

\begin{tabular}{|c|c|c|c|c|c|c|}
\hline \multicolumn{2}{|c|}{ Навеска } & $\mathrm{NaHCO}_{3}$ & $\mathrm{CdCO}_{3}$ & \multicolumn{2}{|c|}{ Площадь эффекта } & \multirow{3}{*}{$\begin{array}{c}\text { Полученный } \\
\text { тепловой эф- } \\
\text { фект CdCO, } \\
\text { кал/r }\end{array}$} \\
\hline $\mathrm{NaHCO}_{3}$ & $\mathrm{CdCO}_{3}$ & \multirow{2}{*}{\multicolumn{2}{|c|}{ по всей навеске, $\%$}} & $\mathrm{NaHCO}_{3}$ & $\mathrm{CdCO}_{3}$ & \\
\hline \multicolumn{2}{|c|}{$r$} & & & \multicolumn{2}{|c|}{$\mathrm{cm}^{2}$} & \\
\hline $\begin{array}{l}0,180 \\
0,135\end{array}$ & $\begin{array}{l}0,276 \\
0,241\end{array}$ & $\begin{array}{l}9,5 \\
7,1\end{array}$ & $\begin{array}{l}14,3 \\
12,7\end{array}$ & $\begin{array}{r}11,2 \\
8,4\end{array}$ & $\begin{array}{l}9,4 \\
8,2\end{array}$ & $\begin{array}{l}-105,0 \\
-105,8\end{array}$ \\
\hline & & & & \multicolumn{2}{|c|}{ Среднее значение } & $-105,4$ \\
\hline
\end{tabular}

Рассчитанное на основании опытных данных количество тепла, необходимое для разложения 1 г карбоната кадмия, равнялось $-105,4$ кал/г, по литературным же данным [7] оно равняется -130 кал/г (-22,44 ккал/моль).

На основании опытных и литературных данных вычислен коэффи циент температурного пересчета для перепада температур 140/430 который равняется $1,23\left(\frac{-130 \text { кал/г }}{-105,4 \text { кал/г }}\right)$.

Поскольку температура термического разложения органическог вещества сланца-кукерсита близка к температуре разложения карбоната кадмия, при работе со смесью горючих сланцев с бикарбонатом натрия можно использовать полученный выше коэффициент температурного пересчета $(1,23)$ и производить расчет по формуле

$$
Q=1,23 Q_{1} \frac{m_{1} s}{m S_{1}},
$$


где $Q$ - определяемый тепловой эффект изменения исследуемого вещества (в данной работе - разложения органического вещества образцов горючего сланца) в расчете на 1 г сланца; $Q_{1}$ - тепловой эффект эталонного вещества (в данной работе $\mathrm{NaHCO}_{3}$ ) в расчете на $1 \mathrm{r} ; m$ - навеска исследуемого вещества (сланца); $m_{1}$ - навеска эталонного вещества; $S$ - площадь, занимаемая тепловым эффектом исследуемого вещества; $S_{1}$ - площадь, занимаемая тепловым эффектом эталонного вещества.

Исследование проводилось на образцах сланца-кукерсита, содержащих от 25 до $88 \%$ органического вещества. Результаты анализа исследованных образцов приведены в табл. 2. Все исследованные образцы, за исключением сланцевого концентрата, полученного обогащением в тяжелой жидкости, представляют собой натуральные пробы сланца, взятые из шахты «Кивиыли» и из разреза № 1 открытых разработок «Вийвиконна».

Таблица 2

Характеристика исследованных проб сланца-кукерсита

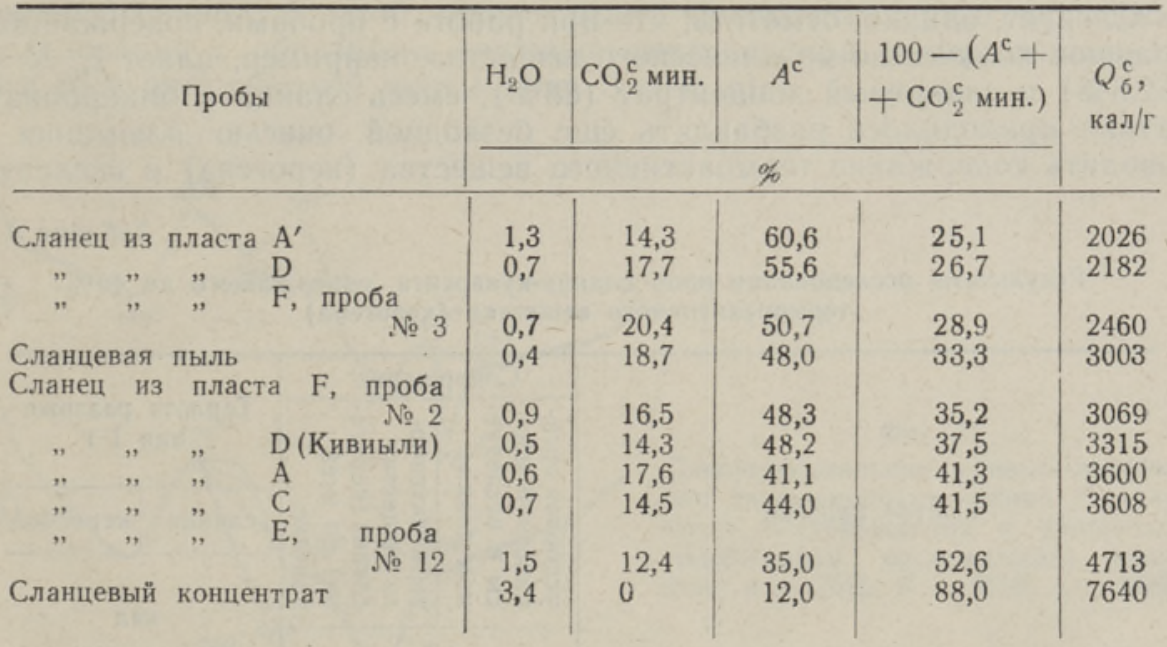

Образцы сланца растирались в тонкий порошок и высушивались в термостате при температуре $115^{\circ} \mathrm{C}$. Средние результаты параллельных опытов, проведенных со смесями образцов сланца с бикарбона том натрия, а также со смесями сланцевого концентрата с бикарбонатом натрия, разбавленными безводной окисью алюминия, приведены в табл. 3. Из этой таблицы видно, как изменяется количество тепла, необходимое для термического разложения 1 г сланца различных проб. При пересчете на количество калорий, необходимых для термического разложения 1 г керогена сланца-кукерсита, во всех пробах эта величина лежала в пределах $-122 \div-128$ кал; среднее значение теплоты разложения равняется $-125,4 \pm 1,7$ кал. Расхождение данных, полученных на разных образцах, не превышает $2,7 \%$.

На фиг. 2 показана зависимость теплоты разложения проб сланцакукерсита от содержания в нем условной органической массы (на основании данных табл. 3). Как видно из графика, эта зависимость практически линейна, следовательно, основное условие линейной зависимости состав - площадь в данных опытах соблюдалось и величину $-125 \pm 2$ кал (получена в результате округления: $-125,4 \pm 1,7$ ) 
можно считать действительно равной теплоте разложения 1 г органического вещества сланца в условиях свободного удаления парогазовой смеси из зоны разложения.

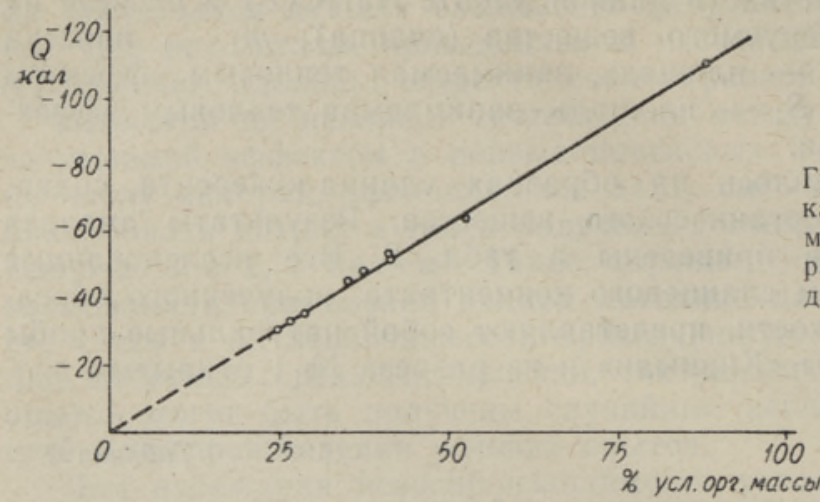

Фиг. 2.

График зависимости количества калорий, необходимых для термического разложения $1 \mathrm{r}$ образцов сланца-кукерсита, от содержания в них органической массы.

Следует, однако, отметить, что при работе с пробами, содержащими большое количество органического вещества, например, пласт Е, № 12 $(52,6 \%)$ и сланцевый концентрат $(88 \%)$, смесь сланца и бикарбоната натрия приходилось разбавлять еще безводной окисью алюминия и доводить содержание термоактивного вещества (керогена) в исследуе-

Таблица 3

Результаты исследования проб сланца-кукерсита, содержащего до $40 \%$ термореактивного вещества (керогена)

\begin{tabular}{cc|c|c|c|c|c}
\hline & \multicolumn{2}{|c|}{ Содержание } & \multicolumn{2}{c}{ Теплота разложе- } \\
ния 1 г
\end{tabular}

* Среднее отклонение от среднего значения:

$$
\frac{1,4+1,4+2,4+0,6+2,6+2,6+1,6+0,6+3,4+0,6}{10}=\frac{17,2}{10} \approx 1,7 .
$$


мой навеске до 25-30\%. При работе с навесками, содержащими более $40 \%$ термоактивного вещества, после удаления парогазовой фазы продуктов термического разложения происходило резкое изменение массы исследуемой навески и линейной зависимости состав - площадь не наблюдалось.

Определение описанным методом теплоты разложения органического вещества диктионемового сланца затрудняется из-за целого ряда неизвестных процессов, протекающих при нагревании образца диктионемового сланца, что затрудняет даже качественную оценку термограмм. Трудно также подобрать эталонное вещество, так как при рассмотрении дифференциальной кривой нагревания диктионемового сланца очень трудно выбрать температурный интервал, при котором не происходили бы те или иные (к сожалению, еще не изученные) процессы, сопровождающиеся тепловыми эффектами.

Ввиду всего сказанного, прежде чем приступить к определению теплоты разложения, необходимо было попытаться определить, какой же именно эффект (в каком температурном интервале) обусловлен процессом термического. разложения органического вещества диктионемового сланца. С этой целью были проведены термографические исследования с образцами диктионемового сланца, содержащими 16 , 48 и $86 \%$ органической массы (фиг. $3 a, \sigma, в)$.

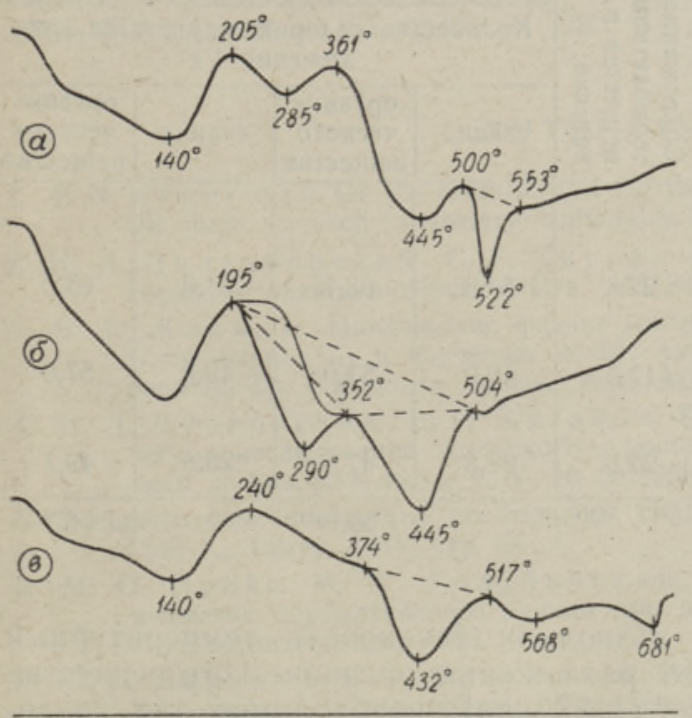

Фиг. 3.

Дифференциальные кривые нагревания диктионемового сланца Маардуского месторождения с различным содержанием органического вещества: $a-16 \% ; \sigma-48 \% ; в-86 \%$.

При внимательном изучении этих термограмм легко заметить, что в области температур $200-500^{\circ}$, помимо ожидаемого эндотермического эффекта разложения органического вещества имеется некоторый экзотермический эффект, обусловленный изменениями одной из минеральных частей сланца, удаляемой при обогащении. Так, в сланце, содержащем $16 \%$ органического вещества, он имеет сравнительно большую величину в интервале температур $285-361^{\circ}$, а в обогащенном до $86 \%$ образце - всего лишь едва заметную остановку основного эндотермического эффекта при $374^{\circ}$. Относительная площадь эффекта, существующего в интервале температур $370-508^{\circ}$, увеличивается с повышением содержания органической массы. На основании этих данных можно сделать вывод, что процесс разложения органического 
вещества диктионемового сланца носит эндотермический характер и протекает в интервале температур $240-374^{\circ}$ менее интенсивно, а начиная с $374^{\circ}$ идет бурное разложение органического вещества.

Такая растянутость процесса при $240-374^{\circ}$ чрезвычайно затрудняет количественное определение. В связи с этим опыты, проведенные на смеси образцов обогащенного диктионемового сланца и бикарбоната натрия, позволили рассчитать только количество тепла, затрачиваемого на разложение органического вещества сланца в интервале температур $350-500^{\circ}$. Добавка бикарбоната натрия сильно искажает величнну эффекта при температуре $240-350^{\circ}$; для обогащенного до $86 \%$ концентрата он сведется практически к нулю. Столь же затруднительными оказались расчеты этой площади на отдельно снятых образцах концентрата сланца, содержащего $50 \%$ органического вещества. Количественные данные, полученные в результате эксперимента, приведены в табл. 4.

Таблица 4

Результаты термографического исследования различных проб диктионемового сланца и их смесей

\begin{tabular}{|c|c|c|c|c|c|c|}
\hline \multirow{3}{*}{ Пробы сланца } & \multirow{3}{*}{ 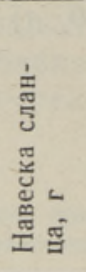 } & \multirow{3}{*}{ 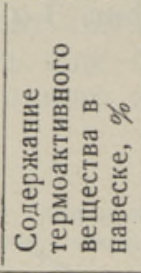 } & \multicolumn{2}{|c|}{$\begin{array}{c}\text { Ограничение пло- } \\
\text { щади эффекта пря- } \\
\text { мой линией } \\
\end{array}$} & \multicolumn{2}{|c|}{$\begin{array}{l}\text { Ограничение пло- } \\
\text { щади эффекта вол } \\
\text { нообразной линией }\end{array}$} \\
\hline & & & \multicolumn{4}{|c|}{$\begin{array}{c}\text { Количество калорий, идущее на раз- } \\
\text { ложение } 1 \mathrm{r}\end{array}$} \\
\hline & & & сланца & $\mid \begin{array}{c}\text { органи- } \\
\text { ческого } \\
\text { вешества }\end{array}$ & сланца & $\begin{array}{c}\text { органи- } \\
\text { ческого } \\
\text { вещества } \\
\end{array}$ \\
\hline \multirow{3}{*}{$\begin{array}{l}\text { 86\%-ный концентрат дик- } \\
\text { тионемового сланца }+ \\
+\mathrm{NaHCO}_{3}+\mathrm{Al}_{2} \mathrm{O}_{3} \\
\text { 86\%-ный концентрат дик- } \\
\text { тионемового сланца }+ \\
+\mathrm{Al}_{2} \mathrm{O}_{3} \\
48 \% \text {-ный концентрат дик- } \\
\text { тионемового сланца }+ \\
+\mathrm{NaHCO}_{3}+\mathrm{Al}_{2} \mathrm{O}_{3}\end{array}$} & 0,300 & 22,4 & 54,3 & 63,1 & 54,6 & 63,5 \\
\hline & 0,266 & 17,5 & 49,0 & 57,0 & 49,0 & 57,0 \\
\hline & 0,607 & 22,0 & 22,8 & 47,5 & 23,8 & 49,7 \\
\hline Среднее заачение & & & & 55,9 & & 56,7 \\
\hline
\end{tabular}

Проведенные исследования позволили установить температурный интервал процесса термического разложения органического вещества диктнонемового сланца и тепло (-57 кал), необходимое для разложения 1 г органического вещества диктионемового сланца в интервале температур $370-500^{\circ}$.

На основании проделанных опытов (всего около 80), проведенных на образцах сланца-кукерсита, содержащих различное количество органической массы, и на образцах обогащенного диктионемового сланца сделаны нижеследуюшие выводы.

1. Для определения теплоты термического разложения органического вешества сланца-кукерсита целесообразно применять количественную термографию, метод определения тепловых эффектов путем измерения площадей соответствующих эффектов на термограмме смеси точных навесок вещества, имеющего известный тепловой эффект, и исследуемого вещества. 
2. При определении теплоты разложения органического вещества сланца количественной термографией следует использовать навески, содержащие 25-33\% термоактивного вещества (керогена сланца).

3. Теплота термического разложения керогена сланца-кукерсита в процессе равномерного нагревания при свободном удалении парогазовой фазы равна - $125 \pm 2$ кал/г.

Теплота термического разложения керогена проб сланца-кукерсита с различным содержанием органической массы может быть рассчитана по формуле

$$
-\frac{125 \text { О.в. }}{100}[\text { кал/г], }
$$

где О.в. - содержание условной органической массы в сланце, $\%$.

4. Изучением термограмм диктионемового сланца и его концентратов установлено, что в области температур $200-500^{\circ}$, помимо эндотермического процесса разложения органического вещества диктионемового сланца, в необогащенных пробах происходит некоторый экзотермический процесс, обусловленный изменением минеральной части.

5. Теплота разложения органического вещества диктионемового сланца (при линейном подъеме температуры) в интервале температур $370-500^{\circ}$ равна - 57 кал/г.

\section{ЛИТЕРА Т У РА}

1. P. N. Kog e rm a n, On the chemistry of the Estonian oil shale kukersite, a monograph, Oil shale research laboratory University of Tartu, Bull. No. 3, 1931.

2. Н. Л. Дил акторский, О. Г. Кир рет и Ю. И. Э йзен, Термический анализ горючего сланца-кукерсита, Изв. АН ЭССР, Т. II, № 1, 1953, стр. 103.

. Б. К. Кли мов, Приложение физико-химического анализа - термографнческого исследования - к изучению углей, Химия и генезис твердых горючих ископаемых, Тр. I Всесоюз. совеш., Изд. АН СССР, 1953, стр. 235.

4. Н. Л. Л уцковская, Е. И. К а за ков, Комплексное термографическое и химическое исследование эстонского сланца-кукерсита, Изв. АН ЭССР. Серия техн. и физ.-мат. наук, т. V, № 2, 1956, стр. 129.

5. Энергетическое совещание по горючим сланцам Эстонской ССР. 28-30 октября 1946 г., Тарту, 1948, стр. 56.

6. M. О. Прей с, M. A. Голубинская, Теплота разложения органического вещества прибалтийского сланца при полукоксовании, Тр. ВНИИПС, вып. 3 Л., Гостоптехиздат, 1955.

7. Ю. П. Б а р к и й, Н. Г. Ф и д м ан и Р. Б. Ив ан и к а я, Термографическая калориметрия в простейшем оформлении, Тр. совещ. по термографии (Казань, 1953), М.-Л., Изд. АН СССР, 1955.

8. Р. Г. В алдек, Н. Л. Л ццковская и Ю. И. Э йзен, Изучение тепловых хаукеритного и диктионемового сланшев и твердых продуктов их термической переработки, НТО Ин-та энергетики АН ЭССР, Таллин, 1958.

Институт энергетики Академии наук Эстонской ССР
Поступила в редакцию 8. V 1960 


\title{
EESTI PÓLEVKIVI ORGAANILISE AINE LAGUNEMISSOOJUSEST
}

\author{
R. Valdek ja N. Lutskovskaja, \\ tehniliste teaduste kandidaadid
}

J. Eisen

Resümee

Põlevkivi termilise töötlemise tööstuslikes agregaatides toimuvate protsesside soojuskulu arvestuseks on vaja teada põlevkivi orgaanilise aine (kerogeeni) lagunemissoojust.

Käesolevas töös määrati lagunemissoojused nii kukersiidi kui ka diktüoneemakilda proovidele kvantitatiivse termografeerimisega.

Kukersiidi kerogeeni lagunemissoojuseks saadi ühtlasel kuumutamisel, s.t. temperatuuri pideval tōusul ( $9^{\circ}$ minutis), auru-gaasi faasi vabal eraldumisel $-125 \mathrm{cal} \pm 2 \mathrm{cal} / \mathrm{g}$.

Diktüoneemakilda ja tema kontsentraatide termogrammide uurimisel selgus, et $200-500^{\circ}$ temperatuuri piirides kulgeb diktüoneemakilda orgaanilise aine endotermilise lagunemisprotsessi kôrval rikastamata proovide puhul veel teatav eksotermiline protsess, mis on tingitud mineraalosas toimuvaist muutustest.

Diktüoneemakilda orgaanilise aine lagunemissoojuseks saadi (lineaarse temperatuuritõusu puhul) $370-500^{\circ}$ temperatuuri piirides $-57 \mathrm{cal} / \mathrm{g}$.
Eesti NSV Teaduste Akadeemia
Energeetika Instituut
Saabus toimetusse
18. V 1960

\section{ON THE DECOMPOSITIONAL HEAT OF THE ORGANIC MATTER IN ESTONIAN OIL SHALE}

\section{R. Valdek, N. Lutskovskaya, J. Eisen}

\section{Summary}

In order to determine the expenditure of heat at the thermal processing of oil shale in industrial aggregates, it is necessary to find out the decompositional heat of the organic matter (kerogen) in oil shale.

In the present study the decompositional heat was determined for samples of kukersite and dictyonema shale, with the help of quantitative thermography.

The decompositional heat of kukersite kerogen, at continued heating, i.e. a constant rise of temperature ( $9^{\circ}$ per minute), and at a free separation of the steam and gas phase was found to be $-125 \mathrm{cal} \pm 2 \mathrm{cal} / \mathrm{g}$.

An examination of thermograms for dictyonema shale and its concentrates showed that in addition to the endothermal decompositional process of the organic matter of dictyonema shale at temperatures ranging within $200-500^{\circ}$ a certain exothermal process takes place in the case of unconcentrated samples, as a result of changes in the mineral compound.

The decompositional heat of the organic matter of dictyonema shale (in the case of a linear rise of temperalure) within the limits of $370-500^{\circ}$ was determined to be $-57 \mathrm{cal} / \mathrm{g}$.

Academy of Sciences of the Estonian S.S.R., Institute of Energetics

Received May 18 th, 1960 